Albrecht, E \& Maciel, MD. (2020). STS Education and Critical Mathematics Education in the guidelines for undergraduate courses in Mathematics. Research, Society and Development, 9(7): 1-17, e583974308.

\title{
Educação CTS e Educação Matemática Crítica nas diretrizes para os cursos de
}

\section{Licenciatura em Matemática}

STS Education and Critical Mathematics Education in the guidelines for undergraduate courses in Mathematics

\section{Educación CTS y Educación Matemática Crítica en las directrices para cursos de Licenciatura en Matemáticas}

Recebido: 07/05/2020 | Revisado: 11/05/2020 | Aceito: 19/05/2020 | Publicado: 30/05/2020

\section{Evonir Albrecht}

ORCID: https://orcid.org/0000-0002-0128-4290

Universidade Federal do ABC, Brasil

E-mail: evonir.albrecht@ufabc.edu.br

Maria Delourdes Maciel

ORCID: https://orcid.org/0000-0002-6821-5185

Universidade Cruzeiro do Sul, Brasil

E-mail: delourdes.maciel@gmail.com

\section{Resumo}

A formação do professor de matemática é alvo de diferentes investigações e críticas. Alguns estudos detalham a formação tecnicista exacerbada, outros a falta de vínculo com a prática. Com base em tais aspectos, a Educação CTS (Ciência, Tecnologia e Sociedade) e a Educação Matemática Crítica apresentam-se como possíveis caminhos para o uso da Matemática de forma consciente e que auxilie na compreensão do entorno e na tomada de decisões. Neste contexto, a questão balizadora deste trabalho investiga se: Há aproximações entre os documentos oficiais que norteiam os cursos de Formação de Professores em Matemática e os pressupostos teóricos da Educação CTS e Educação Matemática Crítica? Para responder esta questão, estabelecemos como objetivo analisar a Formação do Professor de Matemática pautado em uma análise dos documentos balizadores para a construção dos currículos dos Cursos de Licenciatura em Matemática, a saber, o Parecer CNE/CES 1.302/2001, que define as Diretrizes Curriculares Nacionais para os Cursos de Matemática, Bacharelado e Licenciatura e a Resolução CNE/CES 3, de 18 de fevereiro de 2003, que estabelece as Diretrizes Curriculares para os cursos de 
Matemática, ambos documentos públicos disponíveis no site do Ministério da Educação. Estes foram analisados a luz da literatura que apresenta a Educação CTS e a Educação Matemática Crítica. A Metodologia utilizada é de caráter qualitativo e de análise documental. Os resultados apontam que explicitamente, há poucas orientações neste contexto, focando mais na formação de temas específicos que ligados à temática apresentados na questão que baliza o trabalho.

Palavras-chave: Formação de Professores; Educação CTS; Educação Matemática Crítica.

\section{Abstract}

The formation of the mathematics teacher is the target of different investigations and criticisms. Some studies detail the exacerbated technical training, others the lack of connection with the practice. Based on such aspects, STS Education (Science, Technology and Society) and Critical Mathematical Education present themselves as possible ways to use Mathematics consciously and that helps in understanding the environment and in decision-making. In this context, the guiding question of this work investigates whether: Are there any similarities between the official documents that guide the Teacher Education courses in Mathematics and the theoretical assumptions of STS Education and Critical Mathematical Education? To answer this question, we set ourselves the objective of analyzing the Mathematics Teacher Training based on an analysis of the guiding documents for the construction of the curricula of the Mathematics Degree Courses, namely, the CNE / CES Opinion 1.302 / 2001, which defines the Guidelines National Curricula for Mathematics, Bachelor and Licentiate Courses and Resolution CNE / CES 3, of February 18, 2003, which establishes the Curriculum Guidelines for Mathematics courses, both public documents available on the website of the Ministry of Education. These were analyzed in the light of the literature that presents STS Education and Critical Mathematical Education. The methodology used is of a qualitative and documentary analysis. The results show that there are explicitly few guidelines in this context, focusing more on the formation of specific themes that are linked to the theme presented in the question that guides the work.

Keywords: Teacher Education; STS Education; Critical Mathematics Education.

\section{Resumen}

La formación del profesor de matemáticas es objeto de diferentes investigaciones y críticas. Algunos estudios detallan la formación técnica exacerbada, otros la falta de conexión con la práctica. En base a tales aspectos, la Educación CTS (Ciencia, Tecnología y Sociedad) y la Educación Matemática Crítica se presentan como posibles formas de usar las Matemáticas de 
manera consciente y eso ayuda a comprender el entorno y la toma de decisiones. En este contexto, la pregunta orientadora de este trabajo investiga si: ¿Hay alguna similitud entre los documentos oficiales que guían los cursos de Formación Docente en Matemáticas y los supuestos teóricos de Educación CTS y Educación Matemática Crítica? Para responder a esta pregunta, nos propusimos el objetivo de analizar la Formación de Profesores de Matemáticas basada en un análisis de los documentos de orientación para la construcción de los planes de estudio de los Cursos de Grado en Matemáticas, a saber, la Opinión 1.302 / 2001 del CNE / CES, que define las Directrices. Currículo nacional de matemática, licenciatura y licenciatura y resolución CNE / CES 3, de 18 de febrero de 2003, que establece las Directrices curriculares para los cursos de matemática, ambos documentos públicos disponibles en el sitio web del Ministerio de Educación. Estos fueron analizados a la luz de la literatura que presenta la Educación CTS y la Educación Matemática Crítica. La metodología utilizada es de análisis cualitativo y documental. Los resultados muestran que hay explícitamente pocas pautas en este contexto, centrándose más en la formación de temas específicos que están vinculados con el tema presentado en la pregunta que guía el trabajo.

Palabras clave: Formación Docente; Educación CTS; Educación Matemática Crítica.

\section{Introdução}

Ao longo do tempo, vários autores (Nacarato, 2006; Fiorentini, 2008; Bianchini, Lima \& Gomes, 2019) têm ressaltado a importância de se repensar a formação de professores. No século passado "o matemático alemão Felix Klein denunciava, em sua célebre obra Matemática elementar de um ponto de vista superior (...), uma alienação entre a formação universitária de professores de matemática e a prática de sala de aula da escola básica. (Giraldo, 2018, p. 37)”. Esse distanciamento entre teoria e prática continua sendo apontando neste século, por autores como Fiorentini et al. (2002), para eles há:

Desarticulação entre teoria e prática, entre formação específica e pedagógica e entre formação e realidade escolar; menor prestígio da licenciatura em relação ao bacharelado; ausência de estudos histórico-filosóficos e epistemológicos do saber matemático; predominância de uma abordagem técnico-formal das disciplinas específicas; falta de formação teórico-prática em Educação Matemática dos formadores de professores. (p. 154).

Todos os problemas que foram apontados por Fiorentini et al. (2002) na primeira década 
deste milênio parecem continuar interferindo diretamente no ensino e aprendizagem em nossas escolas. Esta questão também é ressaltada novamente em um artigo intitulado "Formação de professores de matemática: para uma abordagem problematizada", no qual os autores apresentam alguns aspectos, que parecem ainda estarem presentes na formação atual.

O fato de questões semelhantes - que revelam cenários de ruptura entre as formas como professores de matemática têm sido formados e a formação efetivamente necessária para o ensino da disciplina na escola básica - emergirem em contextos culturais e em tempos diferentes indica a complexidade do tema. (Giraldo, 2018, p. 38 ).

Moreira e Ferreira (2013) afirmam que frequentemente se defende que o futuro professor de matemática tenha uma formação sólida na área específica, porém, não há explicitação sobre o que constitui esta solidez e quais seriam os impactos na prática profissional do docente. Esta formação sólida, poderia auxiliar a rever ou minimizar diferentes problemas presentes atualmente na Educação, mas, pode não ser o único, ou ainda, nem ser o maior problema. Na construção das ementas e propostas para as licenciaturas há uma recomendação mínima de temas, mas, a grande maioria das temáticas curriculares é inserida através de discussões nos diferentes núcleos ou outros órgãos consultivos aos cursos. Neste contexto, Nacarato (2006), destaca que as “(...) pesquisas revelam que os projetos mais bem-sucedidos de licenciatura são aqueles em que seus membros estão engajados e comprometidos com a formação docente (p.134).” Bianchini, Lima e Gomes (2019), ressaltam que:

No que diz respeito à formação inicial do professor de Matemática, em primeiro lugar as pesquisas indicam que aqueles que elaboram as matrizes curriculares de tais cursos e aqueles que as colocam em prática devem levar em consideração as especificidades do profissional que se deseja formar, o que engloba a necessidade de diferenciar entre a for- mação de professores de Matemática e a de bacharéis em Matemática. Além disso, é fundamental proporcionar aos licenciandos a vivência de diferentes abordagens metodológicas no desenvolvimento das atividades propostas. Finalmente, as pesquisas analisadas indicam que é essencial conscientizar o licenciando de que sua formação profissional não se encerra com a graduação. (p. 18, 19).

Esta colocação aponta a necessidade de repensamos a formação docente, e torná-la mais próxima da realidade e do contexto social. Torná-la acessível para compreensão dos alunos nos diferentes níveis da Educação pode auxiliar na superação de dogmas historicamente instituídos, como a de que a "Matemática é difícil". Alguns dados, como os resultados de avaliações em larga escala, como o SARESP 2018 (Sistema de Avaliação do Rendimento Escolar do Estado 
de São Paulo) (São Paulo, 2019) apresentam resultados que podem fomentar estas e outras discussões, que tangenciam a formação docente. Destacamos que, dentre os estudantes que estão terminando o Ensino Médio, 46,6\% apresentaram desempenho considerado abaixo do básico, que correspondem ao domínio de conceitos básicos, dentre eles as quatro operações; 47,5\% apresentam desempenho considerado básico; 5,6\% deles têm conhecimento adequado para a série; apenas 0,3\% apresentam conceitos acima do esperado, enquadrando-se no nível avançado (São Paulo, 2019). Para compreender a nomenclatura, apresentamos o Quadro 1:

Quadro 1 - Classificação e Descrição dos Níveis de Proficiência do SARESP.

\begin{tabular}{|c|c|c|}
\hline Classificação & Níveis de Proficiência & Descrição \\
\hline Insuficiente & $\begin{array}{ll}\text { Abaixo do } \\
\text { Básico }\end{array}$ & $\begin{array}{l}\text { Os alunos, neste nível, demonstram domínio } \\
\text { insuficiente dos conteúdos, competências e } \\
\text { habilidades desejáveis para a série escolar } \\
\text { em que se encontram. }\end{array}$ \\
\hline \multirow[t]{2}{*}{ Suficiente } & Básico & $\begin{array}{l}\text { Os alunos, neste nível, demonstram domínio } \\
\text { mínimo dos conteúdos, competências e } \\
\text { habilidades, mas possuem as estruturas } \\
\text { necessárias para interagir com a proposta } \\
\text { curricular na série subsequente. }\end{array}$ \\
\hline & Adequado & $\begin{array}{l}\text { Os alunos, neste nível, demonstram domínio } \\
\text { pleno dos conteúdos, competências e } \\
\text { habilidades desejáveis para a série escolar } \\
\text { em que se encontram. }\end{array}$ \\
\hline Avançado & Avançado & $\begin{array}{l}\text { Os alunos, neste nível, demonstram } \\
\text { conhecimentos e domínio dos conteúdos, } \\
\text { competências e habilidades acima do } \\
\text { requerido na série escolar em que se } \\
\text { encontram. }\end{array}$ \\
\hline
\end{tabular}

Fonte: SARESP (São Paulo, 2019, p. 15, adaptado).

Os níveis apresentados no quadro 1 explicitam o que é desejado ou esperado para cada nível. Nesta perspectiva, espera-se que os estudantes consigam, em sua maioria, enquadraremse nos níveis adequado e avançado, sendo que o avançado coloca o aluno a frente dos demais e do que se espera, porém, os resultados preocupam, pois mais de $90 \%$ dos egressos do Ensino Médio estão nos níveis Básico ou Abaixo do Básico.

A avaliação da Prova Brasil apontou uma queda no rendimento dos estudantes do Ensino Médio, uma vez que a média passou de 265,5 em 2009, para 264,1 em 2011, 260,0 em 2013 e 259,3 em 2015 (São Paulo, 2016) e em 2017 o índice apresentou uma melhora tendo na média nacional 269,74 e para o estado de São Paulo 274,1 (Brasil, 2019). Estes dados aliados aos resultados das pesquisas na área de Ensino da Matemática (Fiorentini \& Nacarato, 2005; 
Fiorentini, 2008) apontam para a importância de uma reestruturação da Matemática ensinada nas escolas. A reestruturação neste aspecto transcende não apenas a questão dos conceitos abordados nas escolas, mas abarca também a formação inicial e continuada do professor, indo até a formação de quem forma o professor.

Os estudos discutidos nas páginas anteriores apontam que, tanto em Matemática como em outras áreas, há a necessidade de se repensar os processos de ensino, no sentido que os mesmos tenham um caráter mais humano e mais próximo ao cotidiano. Nesta perspectiva, considerando que a Matemática está presente em outras áreas do conhecimento é importante que ela dialogue com a realidade do aluno e se expanda rumo à diferentes conceitos. No entanto, as avaliações externas como o SAEB, tem apontado resultados aquém do esperado para as disciplinas de Matemática. Portanto, torna-se urgente a reflexão sobre novas possibilidades de atuação docente nestas áreas de ensino. Para além da atuação docente, também é importante nos questionarmos se as diretrizes de formação de professores nessa área propiciam o desenvolvimento de ações didáticas críticas e reflexivas.

Compreendemos que uma formação crítica e reflexiva ocorre a partir de pressupostos teóricos que norteiam os processos formativos. Em busca de uma formação mais comprometida com o exercício pleno da cidadania, em nossa trajetória de pesquisa, temos nos aproximado de duas bases teóricas que apontam para esse tipo de formação: a Educação CTS (Ciência, Tecnologia e Sociedade) e a Educação Matemática Crítica. Ambas apresentam convergências ao apontarem para a formação de cidadãos críticos, reflexivos, participativos, atuantes nos processos de mudança e planejamento em seu contexto e na sociedade. Partindo dessas bases, questionamos: há aproximações entre os documentos oficiais que norteiam os cursos de Formação de Professores em Matemática e os pressupostos teóricos da Educação CTS e Educação Matemática Crítica? Partindo dessa questão, neste artigo, o objetivo é relatar os resultados de uma pesquisa na qual foi investigado se os pressupostos da Educação CTS e da Educação Matemática Crítica (EMC) aparecem nas diretrizes dos cursos de Licenciatura em Matemática.

\section{Compreendendo a Educação CTS e sua relação com a Educação Matemática Crítica}

O movimento CTS surgiu a partir de questionamentos sobre o modelo de desenvolvimento científico e tecnológico que dominou o cenário de transformação mundial no século XX. Na educação, o movimento CTS possibilitou o surgimento de críticas ao modelo de 
ensino de ciências voltado para a formação de cientista. Essas críticas provocaram reformulações curriculares.

Após uma euforia inicial com os resultados do avanço científico e tecnológico, nas décadas de 1960 e 1970, a degradação ambiental, bem como a vinculação do desenvolvimento científico e tecnológico à guerra (as bombas atômicas, a guerra do Vietnã com seu napalm desfolhante) fizeram com que a ciência e a tecnologia (C\&T) se tornassem alvo de um olhar mais crítico. Além disso, a publicação das obras A estrutura das revoluções científicas, pelo físico e historiador da ciência Thomas Kuhn, e Silent Spring, pela bióloga naturalista Rachel Carsons, ambas em 1962, potencializaram as discussões sobre as interações entre ciência tecnologia e sociedade (CTS). (Auler \& Bazo, 2001, p.1).

Quando se fala em Educação CTS, se fala também, simultaneamente em movimento interdisciplinar. Neste contexto, como preparar os professores e futuros professores para trabalhar nessa perspectiva? Ao discutir, por exemplo, os desafios que se colocam para o ensino de Ciências no cenário brasileiro, Auler e Bazo (2001) destacam que a formação dos professores é "incompatível com o modelo interdisciplinar presente no movimento CTS".

Este aspecto se dá principalmente pelo fato da formação dos professores das diferentes áreas ser disciplinar, sendo quase inexistente o estímulo ao futuro professor para analisar o conhecimento em um contexto social, mais amplo. Os limites, as fronteiras disciplinares das diferentes disciplinas são bem marcadas e demarcadas. Vários autores (Jantsch \& Bianchetti, 1997; Santome, 1998, Veiga-Neto, 1996) defendem a necessidade de uma formação interdisciplinar aos professores.

A interdisciplinaridade entendida como um processo histórico educacional pressupõe que as relações pessoais no âmbito da escola precisam também ser repensadas. Mais do que isso, as práticas docentes e as certezas podem ser questionadas permanentemente sem que isso represente um descompasso profissional, pelo contrário, a interdisciplinaridade possibilita o repensar do ato de ensinar e aprender, possibilitando ao professor ser um aprendiz e produtor dos mais diversos saberes.

Sabe-se que além das dificuldades de se promover um ensino interdisciplinar, há outro desafio que é a busca de uma formação para se trabalhar com as questões CTS, uma vez que durante a formação inicial esse tipo de formação raramente é oferecido nas diferentes licenciaturas (Cachapuz, 1999). Uma das possibilidades que pode ser pensada para uma formação de maior qualidade pode ser articular os pressupostos da Educação CTS os quais envolvem discussões sobre aspectos sociais, políticos, culturais e subjetivos. Esses pressupostos 
podem ser inseridos no contexto de formação inicial e de práticas educativas desenvolvidas no âmbito das escolas, valorizando o papel do professor e valorizando de fato a prática docente. Luz (2008) ressalta que:

A sociedade desfruta atualmente de conquistas científicas e tecnológicas advindas das mais diversas áreas de conhecimento, tais como comunicação, medicina, agricultura, sistemas de produção, entre outros. Grande parte destas conquistas afeta diretamente muitos setores que fazem parte do nosso cotidiano, merecendo destaque a área da Educação. (p.15).

Desta forma, ao se pensar em realizar um ensino a partir da Educação CTS, o professor compromete-se com uma postura interdisciplinar na qual o trabalho acontecerá integrado com outras disciplinas. Os pressupostos da Educação CTS estão em consonância ao que é recomendado na Educação Matemática Crítica. Sbrana (2017), em sua dissertação de mestrado, apresenta uma aproximação importante entre a Educação CTS e a EMC, conforme o Quadro 2.

Quadro 2 - Aproximação da Abordagem CTS e EMC.

\begin{tabular}{|c|c|}
\hline ABORDAGEM CTS & EMC \\
\hline Alfabetização Científica & Alfabetização Matemática \\
\hline Leitura Crítica do Mundo & Interpretação da realidade \\
\hline Participação Consciente e Ativa & $\begin{array}{l}\text { Organizar-se para intervir no } \\
\text { Contexto Social e Político }\end{array}$ \\
\hline Contextualização & Cenários de Investigação \\
\hline Diálogo com Outros Conhecimentos & $\begin{array}{ll}\text { Diálogo com } & \text { Outros } \\
\text { Conhecimentos } & \end{array}$ \\
\hline
\end{tabular}

Fonte: (Sbrana, 2017, p.56).

Este quadro, foi construído para apontar como "a abordagem CTS e a EMC se aproximam, buscando uma analogia entre alguns conceitos da abordagem CTS e da EMC." (Sbrana, 2017, p. 56). São termos e definições adotados na abordagem das duas teorias e, o quadro 2 , tenta sistematizar uma possível compreensão para aproximá-las, visto que ambas apresentam definições semelhantes para as temáticas apresentadas, não sendo compreendidas como sinônimos, mas, como aproximações, reforçado pelo fato de que em poucas situações a Educação CTS é utilizada ou inserida na Educação Matemática.

Segundo Skovsmose (2008), a EMC tenta propiciar aos indivíduos uma formação 
crítica, para que possam interpretar a realidade com o intuito de intervir nos contextos social e político se necessário, possibilitando, quando entendida sob a perspectiva crítica, provocar transformações de ordem científica, tecnológica e social. Borba (2011 $\left.{ }^{1}\right)$ destaca que a Educação Matemática Crítica prioriza os “aspectos políticos da Educação Matemática”, na perspectiva de uma Educação transformadora, por assim dizer, libertadora.

Neste contexto, ressalta-se que, como em outras áreas, como no campo das outras Ciências, a Matemática também não é neutra. Borba e Skovsmose (2001) destacam que as verdades matemáticas também podem ser influenciadas por diferentes interesses. Para Pinheiro e Bazzo (2009):

Longe de ser apenas uma ferramenta que auxilia as demais Ciências ou um amontoado de fórmulas e regras, a Matemática se constitui em conhecimento que pode nos auxiliar na compreensão do desenvolvimento da Ciência e da Tecnologia, sendo, muitas vezes, a balizadora e responsável pelas tomadas de decisões em torno de vários fenômenos científico-tecnológicos. (p. 04).

O enfoque em situações mais próximas ao cotidiano, com vistas a tomada de decisão, pode oportunizar a construção de postura crítica em relação às diferentes situações vivenciadas no dia-a-dia, possibilitando a formação de um cidadão pleno e atuante. Investigar e propor maneiras para desmistificar e aproximar a Matemática da realidade na qual os alunos estão inseridos, são propostas que atendem aos pressupostos da Educação CTS e EMC.

Ensinar Matemática a partir do questionamento possibilita ao aluno a compreensão de que a Matemática não está pronta e acabada, mas que pode ser modificada e visualizada em situações corriqueiras. Utilizar questionamentos no processo de ensino não significa que deixemos os conteúdos mais formais de lado, mas que a formalidade matemática não seja a única proposta abordada. Tal situação prejudica e amedronta os alunos que buscam aprender esta disciplina, tornando a escola em muitos casos excludente, ou seja, o aluno não consegue transpor o que ele aprende na Matemática para as situações vivenciadas em seu cotidiano.

Neste aspecto, ressalta-se a importância da reformulação curricular voltada para a formação para a vida. Os documentos oficiais que norteiam a Educação Básica, como a Lei de Diretrizes e Bases da Educação (LDB), (Brasil, 1996) recomendam que a formação do aluno

\footnotetext{
${ }^{1}$ No prefácio do livro de Ole Skovsmose intitulado Educação Matemática Crítica: A Questão da Democracia. Campinas: Papirus, 2011.
} 
“deve ter como alvo principal à aquisição de conhecimentos básicos, a preparação científica e a capacidade de utilizar as diferentes tecnologias relativas às áreas de atuação”. Por fim, tornase necessário repensar a formação do docente para atender as novas demandas, com o objetivo de aproximar às temáticas atuais, em consonância ao que orientam diferentes trabalhos, como apontado em Nacarato (2006) e Bianchini, Lima e Gomes (2019).

\section{Aspectos Metodológicos}

Nesta pesquisa que teve uma abordagem qualitativa realizamos a análise de documentos disponíveis publicamente. Para isso utilizamos os procedimentos da análise documental. Segundo Lüdke e André (1986, p. 38) “a análise documental pode se constituir numa técnica valiosa de abordagem de dados qualitativos seja completando as informações obtidas por outras técnicas, seja desvelando aspectos novos de um tema ou problema".

Foram analisados dois documentos que balizam os cursos de Licenciatura em Matemática no Brasil. Trata-se do Parecer CNE/CES 1.302/2001 (Brasil, 2002), que define as Diretrizes Curriculares Nacionais para os Cursos de Matemática, Bacharelado e Licenciatura e, da Resolução CNE/CES 3, de 18 de fevereiro de 2003 (Brasil, 2003), que estabelece as Diretrizes Curriculares para os cursos de Matemática. A resolução $\mathrm{n}^{\circ} 2$, de $1^{\circ}$ de julho de 2015 (Brasil, 2015), não fez parte da análise por apresentar direcionamentos relacionados aos componentes mais específicos da prática e por compreendermos ser de caráter mais geral. Estes documentos de domínio Público, disponibilizados no site do Ministério da Educação foram lidos e analisados à luz dos pressupostos da Educação CTS e da Educação Matemática Crítica. Ressalta-se que estes dois documentos analisados balizam a construção das ementas e dos projetos políticos pedagógicos dos cursos de licenciatura em matemática no Brasil, alvos deste estudo.

\section{A Educação em Ciência, Tecnologia e Sociedade (CTS) e a Educação Matemática} Crítica (EMC) nas diretrizes para a formação de professores de Matemática

Os balizadores para construção da matriz curricular para formação de professores de matemática são o Parecer CNE/CES 1.302/2001, que define as Diretrizes Curriculares Nacionais para os Cursos de Matemática, Bacharelado e Licenciatura e a Resolução CNE/CES 3, de 18 de fevereiro de 2003, que estabelece as Diretrizes Curriculares para os cursos de Matemática. 
O parecer CNE/CES 1.302/2001 é um documento público, disponível no site do Ministério da Educação, em sua página oficial. Trata-se de um documento com oito páginas e que define as diretrizes que norteiam os cursos de Bacharelado e Licenciatura em Matemática no Brasil. Seus objetivos são:

Servir como orientação para melhorias e transformações na formação do Bacharel e do Licenciado em Matemática e; Assegurar que os egressos dos cursos credenciados de Bacharelado e Licenciatura em Matemática tenham sido adequadamente preparados para uma carreira na qual a Matemática seja utilizada de modo essencial, assim como para um processo contínuo de aprendizagem. (Brasil, 2002, p. 01).

Destacam-se nos objetivos as intencionalidades presentes neste documento, ou seja, servir para a melhoria e transformação dos estudantes e preocupação em assegurar a qualidade do profissional formado. O perfil do egresso esperado para os estudantes, neste documento é dividido, sendo diferente para o bacharel e para o licenciado. Para o licenciado em Matemática, o documento orienta que este tenha:

Visão de seu papel social de educador e capacidade de se inserir em diversas realidades com sensibilidade para interpretar as ações dos educandos. Visão da contribuição que a aprendizagem da Matemática pode oferecer à formação dos indivíduos para o exercício de sua cidadania. Visão de que o conhecimento matemático pode e deve ser acessível a todos, e consciência de seu papel na superação dos preconceitos, traduzidos pela angústia, inércia ou rejeição, que muitas vezes ainda estão presentes no ensinoaprendizagem da disciplina. (Brasil, 2002, p.3).

Nestes três itens, podemos observar a orientação para uma formação dinâmica, em consonância ao que é apresentado na literatura, no tocante à formação de professores. Ressaltase ainda, que este deve estar preparado para a diversidade que com certeza encontrará na sala de aula. No aspecto do empoderamento, o segundo item apresenta a necessidade de oportunizar a formação do indivíduo para o exercício pleno da cidadania, que possa utilizar tais conhecimentos na tomada de decisões. Por fim, a Matemática, difundida por muito tempo, que era acessível para poucos também é questionada, no item três, que defende a democratização deste conhecimento e superação de obstáculos.

O documento também apresenta as competências e habilidades esperadas para o futuro professor de Matemática. Neste contexto, há 11 itens comuns para o futuro licenciado e o futuro bacharel e, ainda apontam mais seis específicos para o licenciando. No tocante aos pressupostos da Educação CTS e/ou da Educação Matemática Crítica, não há uma menção específica no 
documento, apenas alguns indícios, como no item "h) educação abrangente necessária ao entendimento do impacto das soluções encontradas num contexto global e social" (BRASIL, 2002 , p. 4). Este item pode ser associado aos pressupostos anteriormente citados, visto que enseja que o futuro professor vislumbre a visão do todo, frente à tomada de decisões. Dos itens específicos para os licenciandos, podemos destacar:

c) Analisar criticamente propostas curriculares de Matemática para a educação básica; d) Desenvolver estratégias de ensino que favoreçam a criatividade, a autonomia e a flexibilidade do pensamento matemático dos educandos, buscando trabalhar com mais ênfase nos conceitos do que nas técnicas, fórmulas e algoritmos; e) Perceber a prática docente de Matemática como um processo dinâmico, carregado de incertezas e conflitos, um espaço de criação e reflexão, onde novos conhecimentos são gerados e modificados continuamente; (Brasil, 2002, p. 04).

Nestes três itens destacados, em nenhum momento salientam-se explicitamente o uso de questões relacionadas a Educação CTS ou Educação Matemática Crítica. Podemos apontar indícios, como no item c, que ressalta a necessidade de análise crítica, mas, das propostas curriculares para a Educação Básica. Dos itens "d" e "e", podemos destacar que estão em consonância ao que se espera de uma Educação Crítica e libertadora. Skovsmose (2011) reforça que:

Questões educacionais diretrizes poderiam ser: Como pôr os estudantes a par do impacto tecnológico sobre a sociedade? Como tornar os estudantes cientes do papel da matemática como parte de um desenvolvimento tecnológico? Como ter uma ideia das condições básicas para viver em uma sociedade altamente tecnológica? Como refletir sobre a cultura tecnológica? Tais questões podem revelar uma abertura para a educação crítica, e também para a educação matemática. (p. 98).

Observa-se que a tecnologia permeia as questões ligadas ao currículo, ou deveriam permear, não para se construir um modelo de tecnologia, mas, de compreensão sobre a tecnologia. No tocante aos conteúdos, não há qualquer menção aos pressupostos defendidos nesta pesquisa. Algo que vale ser destacado é que as "IES poderão ainda organizar os seus currículos de modo a possibilitar ao licenciado uma formação complementar propiciando uma adequação do núcleo de formação específica a outro campo de saber que o complemente". (Brasil, 2002, p. 07). Neste contexto, a autonomia para inserção de outras disciplinas e que possam oportunizar a inserção de um ou dos dois eixos aqui destacados pode ocorrer, mas depende de cada instituição. Nesta perspectiva, poderemos esbarrar em outros dificultadores, 
como o enxugamento dos currículos ou as adequações ao mínimo necessário, fato este que nem sempre garante a formação almejada.

O segundo documento, a saber, a Resolução CNE/CES 3, de 18 de fevereiro de 2003, que estabelece as Diretrizes Curriculares para os cursos de Matemática, também está disponível na página oficial do Ministério da Educação, possui apenas uma página e, não apresenta nenhuma menção ao tipo de disciplinas que deverão fazer parte do rol da Formação docente. Não apresenta aspectos que possam ser relacionados à Educação CTS ou Educação Matemática Crítica, implícita ou explicitamente.

\section{Considerações}

A formação do professor nos aspectos que relacionam a Educação CTS e a Educação Matemática Crítica continua sendo pouco recomendada, principalmente quando analisamos os documentos que orientam as diretrizes para criação de cursos de Licenciatura em Matemática. Entende-se que os documentos não apresentam teorias, mas, podem apesentar indícios de sua inserção. Neste contexto, ao analisar os documentos oficiais, que orientam os cursos de Formação de Professores em Matemática, verificamos que a Educação CTS e a Educação Matemática Crítica não aparecem de forma explícita nestes documentos, cabendo a cada instituição de ensino, por meio dos projetos pedagógicos dos cursos de Licenciatura em Matemática, fazer ou não apontamentos sobre essas abordagens teóricas nos documentos que balizam estes cursos.

Avanços na formação do docente ocorreram, sem dúvidas. Porém, ainda temos muito a avançar, em relação às políticas formativas, a grade curricular dos cursos de licenciatura e por fim, aproximar os locais de formação docente do chão da sala de aula, para que os diálogos e as necessidades sejam de fato percebidos e incorporados aos diferentes cursos de formação espalhados pelo Brasil, uma vez que a Matemática carrega consigo o estigma de ser difícil, complexa e para poucos. Hoje, percebe-se que por muitas vezes o que definamos como Matemática, pode ser algo dissociado da realidade, sem relação com o cotidiano, com a interpretação de fenômenos ou outros, não auxilia na tomada de decisões, pois, como utilizar o que não sabemos utilizar ou compreender?

Uma possibilidade para compreender e aplicar conceitos na e para a tomada de decisões pode ter origem ao utilizar a Matemática como instrumento para apropriação e compreensão da realidade, para uma leitura crítica de mundo e, diante de adversidades compreender que o conhecimento pode auxiliar a estruturar soluções. 
Mas, qual a necessidade em explicitar tais aspectos? Sem dúvida a explicitação favorece a mobilização para este tipo de trabalho, para compreensão do mundo que estamos inseridos sob uma perspectiva política, na qual cada indivíduo é parte responsável por tudo o que ocorre e que pode alterar o meio que está inserido quando possui conhecimentos para análise e uma tomada de decisão consciente.

As demandas são diversas e não culminam apenas na formação do professor, carecem de discussões de cunho Político, sobre as políticas formativas, aos incentivos necessários a carreira docente, aos investimentos em infraestrutura para as escolas de Educação Básica, enfim, ao reconhecimento da carreira e da profissão. Ressalta-se, que, para a estruturação de novas formas de se conceber a formação docente o ponto de partida é a sala de aula.

\section{Referências}

Auler, D.; Bazzo, W. A. (2001). Reflexões para a implementação do movimento CTS no contexto educacional brasileiro. Ciência \& Educação, 7(1).

Bianchini, B; Lima, G. L.; Gomes, E. (2019). Formação de Professor: reflexões da educação matemática no ensino superior. Educação \& Realidade, Porto Alegre, 44(1).

Borba, M. C.; Skovsmose, O. (2001). A Ideologia da Certeza em Educação Matemática In: Skovsmose, O. Educação Matemática Crítica - A Questão da Democracia. Campinas: Papirus.

Brasil. (1996). Lei no 9.394, de 20 de dezembro de 1996. Lei de Diretrizes e Bases da Educação Nacional. Diário Oficial da União, Brasília, DF, 24 dez. 1996. Acesso em 21 de janeiro de 2020, em http://portal.mec.gov.br/seed/arquivos/pdf/tvescola/leis/lein9394.pdf.

Brasil. (2002). Parecer CNE/CES 1.302/2001 - Homologado. Despacho do Ministro em 4/3/2002, publicado no Diário Oficial da União de 5/3/2002, Seção 1, p. 15. Acesso 21 de janeiro de 2020, em http://portal.mec.gov.br/cne/arquivos/pdf/CES13022.pdf.

Brasil. (2003). Resolução CNE/CES 3, de 18 de fevereiro de 2003.(*) Estabelece as Diretrizes Curriculares para os cursos de Matemática. Acesso em 21 de janeiro de 2020, em http://portal.mec.gov.br/cne/arquivos/pdf/ces032003.pdf. 
Brasil. (2015). Ministério da Educação. Resolução $n^{o} 2$, de $1^{o}$ de julho de 2015. Define as Diretrizes Curriculares Nacionais para a formação inicial em nível superior e para a formação continuada. Acesso em 10 de fevereiro de 2020, em http://portal.mec.gov.br/docman/agosto2017-pdf/70431-res-cne-cp-002-03072015-pdf/file.

Brasil. (2019). Instituto Nacional de Estudos e Pesquisas Educacionais Anísio Teixeira. Relatório SAEB [recurso eletrônico]. - Brasília: Instituto Nacional de Estudos e Pesquisas Educacionais Anísio Teixeira, 2019. Acesso em 12 de fevereiro de 2020, em http://portal.inep.gov.br/documents/186968/484421/RELAT\%C3\%93RIO+SAEB+2017/fef6 3936-8002-43b6-b741-4ac9ff39338f?version=1.0.

Cachapuz, A. F. (1999). Epistemologia e ensino de ciências no pós-mudança conceptual: análise de um percurso de pesquisa. Atas do II ENPEC, Valinhos.

FiorentiniI, D. (2008). Pesquisa e as Práticas de Formação de Professores de Matemática em face das Políticas Públicas. Bolema, Rio Claro, 21(29): 43-70, Acesso em 21 de janeiro de 2020, em: http://www.periodicos.rc.biblioteca.unesp.br/index.php/bolema/article/view/1718/1495>.

FiorentiniI, D.; Nacarato, A. M. (2005). Cultura, Formação e Desenvolvimento Profissional de Professores que ensinam Matemática: investigando e teorizando sobre a prática. São Paulo: Musa.

FiorentiniI, D.; Nacarato, A. M.; Ferreira, A. C.; Lopes, C. S.; Freitas, M. T. Miskulin, R. G. S. (2002). Formação de professores que ensinam matemática: um balanço de 25 anos da pesquisa brasileira. Educação em Revista, Belo Horizonte, (36): 137-160.

Giraldo, V. (2018). Laboratório de Práticas Matemáticas para o Ensino da Universidade Federal do Rio de Janeiro. Revista Ciência e Cultura. Acesso em 15 de fevereiro de 2020, em http://cienciaecultura.bvs.br/pdf/cic/v70n1/v70n1a12.pdf.

Jantsch, A. P.; Bianchetti, L. (1997). Interdisciplinaridade - Para além da filosofia do sujeito. In: Jantsch, A. P.; Bianchetti, L. (Orgs.) Interdisciplinaridade. Para além da filosofia do sujeito. Petrópolis: Vozes. 
Lüdke, M.; André, M. E. D. A. (1986). Pesquisa em educação: abordagens qualitativas. São Paulo: EPU.

Luz, S. C. (2008). O ensino de física no enfoque ciência, tecnologia e sociedade (CTS): uma abordagem da eletricidade a partir do método experimental investigativo. 2008. 237 f. Dissertação (Mestrado em Ensino de Ciências e Matemática)-Universidade Cruzeiro do Sul, São Paulo.

Moreira, P. C.; Ferreira, A. C. (2013). O lugar da matemática na licenciatura em matemática. Bolema, 27(47): 981-1005.

Nacarato, A. M. (2006). A Formação do Professor de Matemática: pesquisa x políticas públicas. Contexto e Educação. Editora Unijuí, (75): 131-153.

Pinheiro, N. M.; Bazzo, W. A. (2009). Caso Simulado no Ensino-Aprendizagem de Matemática: Ensinar sob uma Abordagem Crítica. Bolema, (32):101-122.

Santomé, J. T. (1998). Globalização e interdisciplinaridade: o currículo integrado. Porto Alegre: Artes Médicas.

São Paulo. (2016). Secretaria de Estado da Educação. Sumário Executivo. SARESP, 2016. Acesso em 21 de janeiro de 2020, em http://saresp.fde.sp.gov.br/2016/Arquivos/Sumario_ Executivo_SARESP_2016.pdf.

São Paulo. (2019). Secretaria de Estado da Educação. Sumário Executivo. SARESP, 2018. 2019. Acesso em 10 de fevereiro de 2020, em http://saresp.fde.sp.gov.br/2018/ Arquivos/seed1802_sumario_executivo.pdf.

Sbrana, M. F. C. (2017). A contextualização da matemática a partir da abordagem CTS na Educação Matemática Crítica. 2017. 135 f. Dissertação (Mestrado em Ensino e História das Ciências e Matemática) - Universidade Federal do ABC, Santo André.

Skovsmose, O. (2008). Desafios da Reflexão em Educação Matemática Crítica. Campinas: Papirus. 
Skovsmose, O. (2011). Educação Matemática Crítica: a questão da democracia. 6.ed. Campinas: Papirus.

Veiga-Neto, A. (1996). A ordem das disciplinas. 1996. 344 f. Tese de Doutorado (Programa de Pós-Graduação em Educação) - UFRGS. Porto Alegre.

Porcentagem de contribuição de cada autor no manuscrito

Evonir Albrecht - 70\%

Maria Delourdes Maciel - 30\% 